\title{
Nano- and micro-scale impact testing of zirconia, alumina and zirconia- alumina duplex optical coatings on glass
}

\author{
Ben D. Beake1, Luis Isern ${ }^{2,}$, Debabrata Bhattacharyya ${ }^{2}$, Jose L. Endrino ${ }^{2,3,4}$, Ken \\ Lawson $^{5}$, Trevor Walker ${ }^{5}$ \\ 1 Micro Materials Ltd, Willow House, Yale Business Village, Ellice Way, Wrexham, LL13 7YL, UK \\ 2 School of Aerospace, Transport and Manufacturing, Cranfield University, Bedford, MK43 0AL, UK \\ 3 Basque Center for Materials, Applications \& Nanostructures, UPV/EHU Science Park, Barrio Sarriena s/n, \\ 48940 Leioa, Spain
}

4 IKERBASQUE, Basque Foundation for Science, Plaza Euskadi, 5, Bilbao 48009, , Spain

5 Thin Metal Films, Stroudley Rd, Basingstoke RG24 8UG, UK

* Corresponding author. Email: 1.isernarrom@cranfield.ac.uk.

\begin{abstract}
Optimising the mechanical properties of optical coatings to improve their durability will be critical if they are to be used successfully in harsh environments where they may be subject to degradation by mechanical contact. In this study zirconia, zirconia-alumina duplex and alumina experimental coatings were deposited on soda lime and borosilicate glass and their resistance to repetitive impact under different experimental conditions evaluated in nano- and micro-scale impact tests. The influence of changing probe geometry (sharp and blunt contacts) and applied load on the deformation was studied. Spheroconical indenters were found to be more suitable to study the load sensitivity of the impact response than sharp cube corner indenters. Increased resistance to plastic deformation in the coating-substrate system $\left(H^{3} / E^{2}\right)$ proved detrimental to
\end{abstract}


the damage tolerance to the repetitive nano- and micro-impact tests. To compare the deformation behaviour in nano-impact and nano-scratch, tests were performed using the same spheroconical probe, revealing cracking and blistering of the glass substrate in both types of test. The change in probe depth after the first impact was found to be a very useful metric to effectively compare the evolution of surface damage on continued impact in nano- and microimpact tests at different applied load and/or probe geometry.

Keywords: surface analysis; PVD coatings; fracture behaviour; impact wear; optical; wear testing.

\section{Introduction}

Intrinsically brittle materials are susceptible to damage in mechanical contact, particularly under impact or erosive wear conditions. To simulate impact conditions their resistance to damage is often studied by indentation but there are additional deformation mechanisms operative in cyclic loading conditions that are not observed in static (single cycle) indentation tests [1]. Instrumented laboratory tests such as nano-impact have the potential to aid the development of coating systems with improved damage tolerance. Originally used with sharp cube corner indenters to study hard semi-brittle coatings [2], nano-impact has found applications in testing a wide range of coatings and hard and soft bulk materials [3-5]. In the test the indenter is accelerated to repetitively impact the surface at high strain rate and the progression of impact-induced damage is followed cycle-by-cycle by monitoring the indenter penetration depth. To bridge the gap between nano- and macro-scale, the micro-impact test has been developed, typically employing spheroconical diamond probes with larger impact loads in the micro- range $(\sim 0.5-5 \mathrm{~N})[6]$. The micro-impact test has been used for studying hard coating systems, cemented carbides and bulk metallic glasses [6-9]. Tarrés and co-workers 
have noted that there is an improved intrinsic suitability for examining gradual damage processes when switching from sharp to blunter spherical indenters [10].

Optical coating systems represent a particular challenge since their design must not compromise their functional properties and coating deposition must be performed at temperatures low enough not to degrade the glass substrate. Optimising their mechanical properties to improve their durability will be critical if they are to be used successfully in harsh environments where they may be subject to mechanical contact [11-16]. Improving resistance to damage by retaining some level of elasticity along with hardness should improve performance on duplex coatings, for example, for mirror systems. The mechanical properties of duplex coatings could be engineered in a way not possible with the single layer coating. Small scale testing provides a convenient route to optimisation. For example, ramped load scratch tests have been used to assess fracture strength [15] and repetitive nano-scratch (low cycle nano-wear) tests have been used to simulate abrasion [11-12]. Nano-wear tests on amorphous silica and silicon oxynitride thin films deposited by reactive RF magnetron sputtering on soda lime float glass have shown that their scratch resistance can be tailored by optimising the deposition conditions [11-12].

In this work a set of experimental thin coatings were deposited on soda lime and borosilicate glass and their resistance to repetitive impact studied under different experimental conditions. Apart from the optical properties, the mechanical properties of these coatings play a significant role in the performance of the component, particularly abrasion and impact resistance. Knowledge of the subsurface damage is extremely helpful in ascertaining the mechanical properties of these optical coatings, which is key for applications such as antireflection and coatings for pulsed and continuous laser systems. In a nano-impact test, the severity of the test and positions of peak impact-induced stresses relative to the coating-substrate interface can be controlled by varying the applied load, accelerating distance and the probe geometry. The 
coatings studied represent an ideal brittle system (brittle coating-brittle substrate) to investigate the influence of changing probe geometry (sharp and blunt contacts) and applied load on the deformation process. Both monolayer and duplex coatings were tested. An advantage of the instrumented small-scale test is that automatic multiple test arrays can be scheduled on each sample and the stochastics of the impact behaviour can be conveniently studied. To conveniently compare the coating behaviour in tests at different applied load and/or with different probe geometries, the change in depth after the initial impact (i.e. setting depth at initial impact to zero) was investigated to determine whether it could provide a more useful indicator of the damage evolution than the impact depth.

\section{Experimental}

\subsection{Coating deposition}

Zirconia, zirconia-alumina duplex and alumina experimental coatings were produced. Their composition, film thickness, deposition temperature, substrate and refractive index are summarised in Table 1. Hereafter, for simplicity the samples are referred to by their sample ID given in Table 1. The coatings were deposited with an Edwards 700 vacuum chamber with a 4-hearth electron beam source. Zirconia was pre-melted by electron beam prior to deposition. Since zirconia loses oxygen on evaporation in vacuum the coatings were deposited at 25 and $220{ }^{\circ} \mathrm{C}$ with background oxygen present to maintain stoichiometry. For the duplex coatings, aluminium oxide and zirconia were in separate hearths in the electron beam multi-hearth source, enabling sequential deposition at $220{ }^{\circ} \mathrm{C}$ without breaking vacuum. The alumina coatings were deposited by ion-assisted deposition at $25^{\circ} \mathrm{C}$ with two different oxygen gas flow rates (10 and $15 \mathrm{sccm}$ ) to achieve different ion flux densities. Z270 and Z790 were deposited on microscope slide glass and Z130, AZ145 and AZ170 on float glass. 


\begin{tabular}{|c|c|c|c|c|}
\hline Sample ID & Coating composition & Substrate & $\begin{array}{c}\text { Deposition } \\
\text { temperature } /{ }^{\circ} \mathrm{C}\end{array}$ & $\begin{array}{c}\text { Refractive } \\
\text { index }\end{array}$ \\
\hline $\mathrm{Z130}$ & $130 \mathrm{~nm}$ zirconia & soda lime glass & 220 & 1.90 \\
\hline$\overline{Z 270}$ & $268 \mathrm{~nm}$ zirconia & soda lime glass & 25 & 1.87 \\
\hline$\overline{Z 790}$ & $788 \mathrm{~nm}$ zirconia & soda lime glass & 25 & 1.97 \\
\hline AZ145 & $\begin{array}{c}125 \mathrm{~nm} \text { zirconia top } \\
\text { layer }+20 \mathrm{~nm} \text { alumina } \\
\text { sub-layer }\end{array}$ & soda lime glass & 220 & 1.93 \\
\hline AZ170 & $\begin{array}{c}131 \mathrm{~nm} \text { zirconia top } \\
\text { layer }+40 \mathrm{~nm} \text { alumina } \\
\text { sub-layer }\end{array}$ & soda lime glass & 220 & 1.85 \\
\hline A120 & $118 \mathrm{~nm}$ alumina & $\begin{array}{c}\text { borosilicate } \\
\text { glass }\end{array}$ & 25 & 1.60 \\
\hline A130 & $128 \mathrm{~nm}$ alumina & $\begin{array}{c}\text { borosilicate } \\
\text { glass }\end{array}$ & 25 & 1.60 \\
\hline
\end{tabular}

Table 1. Sample composition and deposition conditions

\subsection{Nanoindentation and nano-scratch}

Nanoindentation, nano-impact, nano-scratch and micro-impact tests were performed with a NanoTest system (Micro Materials Ltd.). To assess the coating system mechanical properties as a function of depth a rapid depth profiling technique was employed. This comprised 40 loadpartial unload cycles to progressively greater depths, with each unloading segment being analysed by standard contact mechanics to determine how the hardness and elastic modulus 
vary with penetration into the thin film systems. To improve the accuracy of hardness data on the thinnest films it was necessary to use a very sharp Berkovich indenter and accurately calibrate this over the $0-100 \mathrm{~nm}$ depth range. For statistical purposes, at least 10 repeat rapid depth profiling tests were performed on each coating system. Hardness measurements at $10 \%$ film thickness and Elastic modulus measurements extrapolated to zero depth (ISO14577 methodology) are reported in Table 2.

Nano-scratch tests were performed on the Z270 and Z790 samples with a $90^{\circ}$ spheroconical diamond indenter with nominal end radius $R$ of $5 \mu \mathrm{m}$. Spherical indentation into fused silica and sapphire determined its actual radius was $R=4.8 \mu \mathrm{m}$. Scratch tests were performed to peak loads of 30 and $60 \mathrm{mN}$ at $1 \mathrm{mN} / \mathrm{s}$ and $5 \mu \mathrm{m} / \mathrm{s}$ to obtain the critical loads for coating failure and to $300 \mathrm{mN}$ at $5 \mathrm{mN} / \mathrm{s}$ and $10 \mu \mathrm{m} / \mathrm{s}$ to investigate substrate fracture at higher load.

\subsection{Nano- and micro-impact testing}

Nano-impact tests were performed on the Z270 and Z790 films with a sharp cube corner diamond indenter at 2-6 $\mathrm{mN}$ coil force, accelerating from $10 \mu \mathrm{m}$ above the surface to produce one impact every 4 s. The $300 \mathrm{~s}$ (75 impact) tests were repeated 10 times at each load, with each subsequent impact $50 \mu \mathrm{m}$ away from the previous test. Each impact cycle comprises several bounces until the probe comes to rest. The "on-load" probe rest depth for every impact is recorded. The initial $\left(h_{1}\right)$ and final $\left(h_{\mathrm{f}}\right)$ depths provide a convenient assessment of the damage tolerance of the system. $300 \mathrm{~s}$ impact tests were performed with the same spherical indenter as used in the scratch tests $(R=4.8 \mu \mathrm{m})$ accelerating from $15 \mu \mathrm{m}$ above the surface. 10 repeat tests were performed at $0.5,1,2,5,10,15,20,25 \mathrm{mN}$ on $\mathrm{Z} 270$ and at $1,2,5,10,15$ and 20 $\mathrm{mN}$ on Z790. A single test was also performed at $25 \mathrm{mN}$ on $\mathrm{Z790.}$

For the impact tests on the other coatings and an uncoated borosilicate glass only spherical indenters were used. $600 \mathrm{~s}$ impact tests (150 impacts) were performed with the $R=4.8 \mu \mathrm{m}$ 
diamond indenter accelerating from $15 \mu \mathrm{m}$ above the surface. Each test was repeated 10 times at $15 \mathrm{mN}$. Tests over a load range of $10-30 \mathrm{mN}$ were run on AZ170 and 5-30 $\mathrm{mN}$ on BS glass with 10 repeats at each load. Micro-impact tests were performed at 4-6 N on AZ145, AZ170 and Z130 with a $100 \mu \mathrm{m}$ end radius spherical probe whose geometry was checked by indentation into fused silica. The accelerating distance was set to $25 \mu \mathrm{m}$ and the test time was 300 s (75 impacts).

\subsection{Other coating characterisation techniques}

SEM images of the impact craters were obtained with the back-scattered detector on a FEI XL30 ESEM in environmental (low $\mathrm{H}_{2} 0$ pressure) mode to enhance contrast between heavier atoms of the coating and the lighter substrate atoms, enabling quantification of the chipped/delaminated region. SEM images of the cross-sections were obtained with the secondary and back-scattered electrons detectors on a TESCAN Vega3, with the samples coated with a $10 \mathrm{~nm}$ layer of gold to enhance image resolution. Optical microscopy images of the impact craters were obtained using a Confocal Scanning Laser Microscopy system from Olympus, model Lext OLS 3100. Refractive index was calculated using data collected by a UV-vis-NIR spectrometer (Jasco V670) and processed by Filmstar software to simulate film interference.

\section{Results}

The nanoindentation results are summarised in Table 2 . The hardness of the zirconia films was 3.9-5.0 GPa, increasing slightly with film thickness. The hardness of the duplex films was 4.24.5 GPa, within the range of the pure zirconia films. Although the alumina films A120 and A130 were harder than the borosilicate glass substrate, they were also significantly stiffer so that their $H / E$ values were lower. In the nano-scratch tests, the critical load for total coating 
failure was $(11 \pm 1) \mathrm{mN}$ on $\mathrm{Z} 270$ and $(52 \pm 4) \mathrm{mN}$ on Z790. The corresponding on-load scratch depths at onset of failure were 140 and $440 \mathrm{~nm}$ respectively. Substrate fracture was observed at higher load on both samples (at $190 \mathrm{mN}$ on Z270 and $200 \mathrm{mN}$ on Z790). The on-load depth at the start of the substrate fracture was $\sim 1470$ and $\sim 2010 \mathrm{~nm}$ respectively. For Z790 it was possible to obtain an estimate of the coating thickness from the residual depth at failure, which was $\sim 795 \mathrm{~nm}$.

\begin{tabular}{|c|c|c|c|c|}
\hline Sample ID & $H(\mathrm{GPa})^{*}$ & $E(\mathrm{GPa})^{*}$ & $H / E$ & $H^{3} / E^{2}(\mathrm{GPa})$ \\
\hline Z130 & 3.9 & 77 & 0.051 & 0.010 \\
\hline Z270 & 4.8 & 98 & 0.049 & 0.012 \\
\hline Z790 & 5.0 & 105 & 0.048 & 0.011 \\
\hline AZ145 & 4.5 & 83 & 0.054 & 0.013 \\
\hline AZ170 & 4.2 & 80 & 0.053 & 0.012 \\
\hline A120 & 8.7 & 111 & 0.078 & 0.053 \\
\hline A130 & 7.7 & 105 & 0.073 & 0.041 \\
\hline BS glass & 6.2 & 67 & 0.093 & 0.053 \\
\hline
\end{tabular}

* Data from load-partial unload tests. To obtain coating properties independent of substrate contribution the hardness was from values at 1/10 relative indentation depth and elastic modulus from extrapolation to zero depth (ISO14577-4). Standard deviation in hardness and elastic modulus by this approach are $\sim 0.1$ and $\sim 2$ GPa respectively.

\section{Table 2. Nanoindentation results}

Illustrative results from 2, 4 and $6 \mathrm{mN}$ nano-impact tests on the $\mathrm{Z} 270$ and $\mathrm{Z790}$ films with the cube corner are shown in Fig. 1(a,b). On Z270 there were few abrupt jumps in displacement 
and typically the impact depth gradually increased to reach a load-dependent plateau, with only very minor inflexions during the gradual depth increase. In contrast, for Z790 the impact depth typically gradually increased to reach an approximately constant value before a sudden increase in depth. For the tests in Fig. 1(b) this failure event occurred on the $7^{\text {th }}$ impact at $6 \mathrm{mN}$, the $17^{\text {th }}$ impact at $4 \mathrm{mN}$, and the $51^{\text {st }}$ impact at $2 \mathrm{mN}$. Although these increases in depth at failure tended to occur after fewer impacts at higher load, the failure behaviour was stochastic. To illustrate this probability distributions of the number of impacts required for failure at 2 and $3 \mathrm{mN}$ on Z790 are shown in the Supplementary Material (figure S1). Despite the stochastic behaviour in the number of impacts required for failure, the final impact depth was much less scattered. Throughout the studied load range the mean final depth data are greater on Z790 than Z270, by an amount close to the difference in thickness between them (Fig. 1(c)). SEM imaging (Fig. 1(d)) showed that in all but one test with the cube corner probe chipping/delamination occurred (the exception being a test at $2 \mathrm{mN}$ on Z790). The chipped/delaminated area was larger for Z790. The difference in final depth between Z270 and Z790 varied little across the load range at $(527 \pm 99) \mathrm{nm}$.

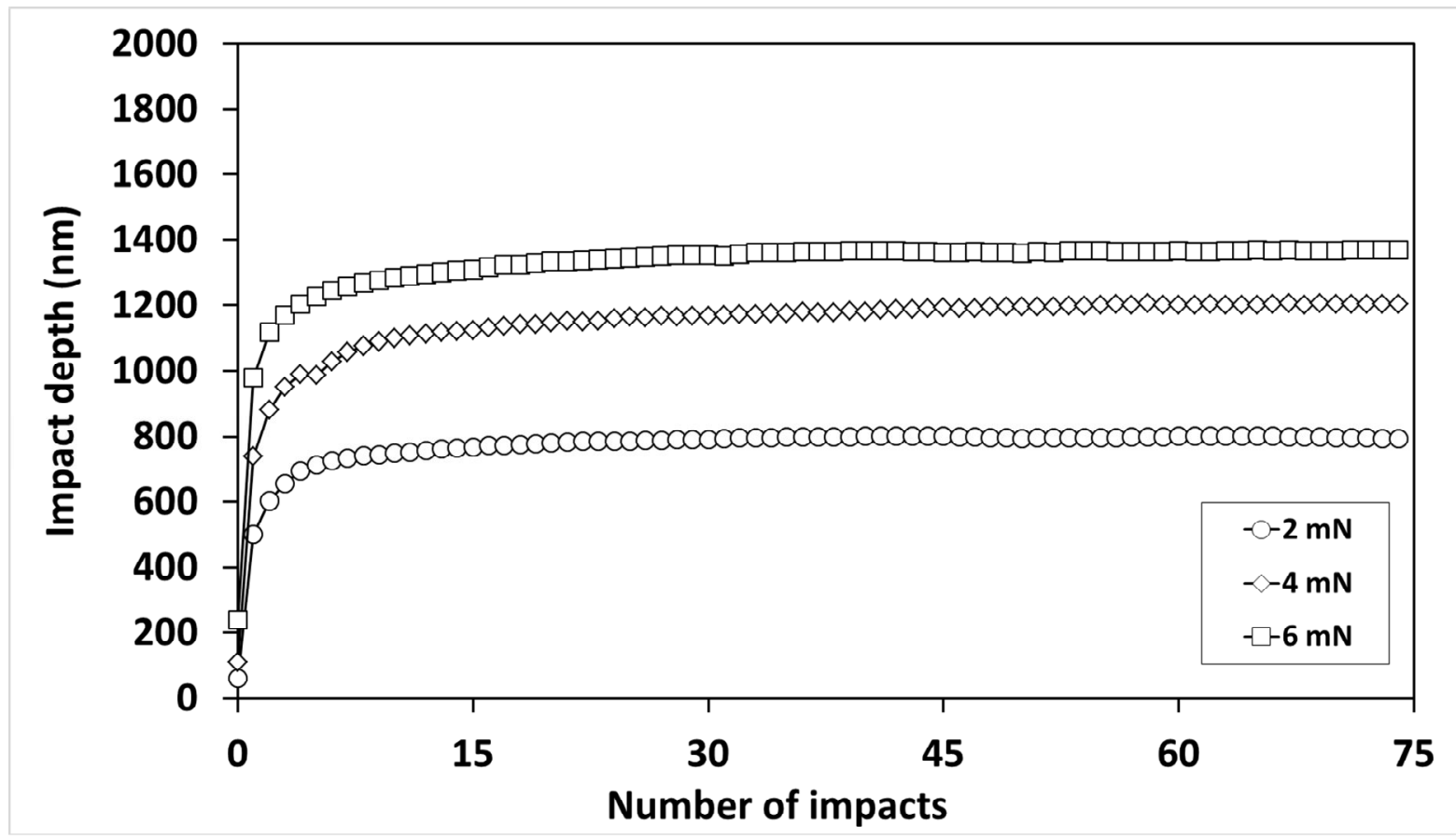


1(a)

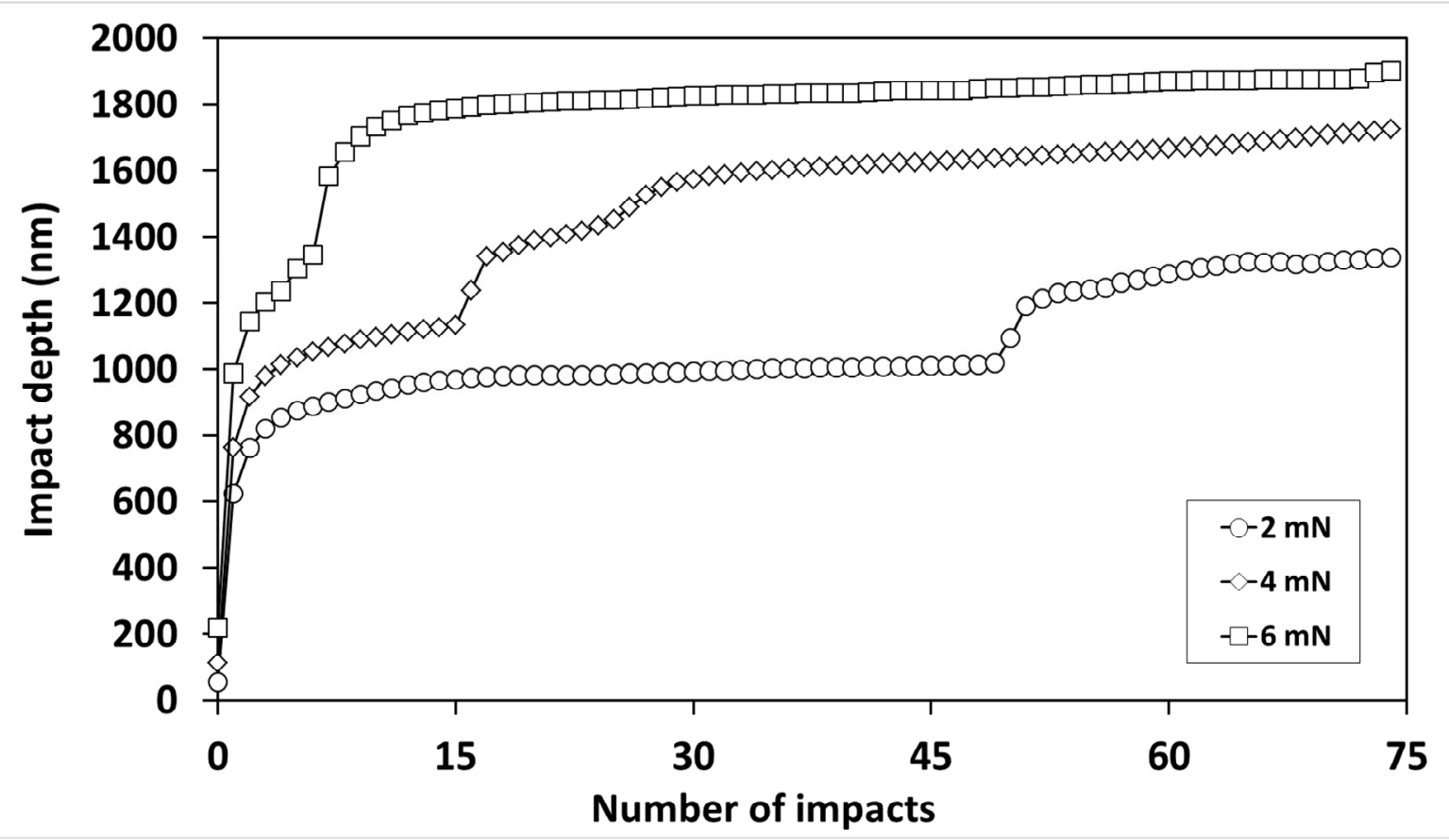

1 (b)

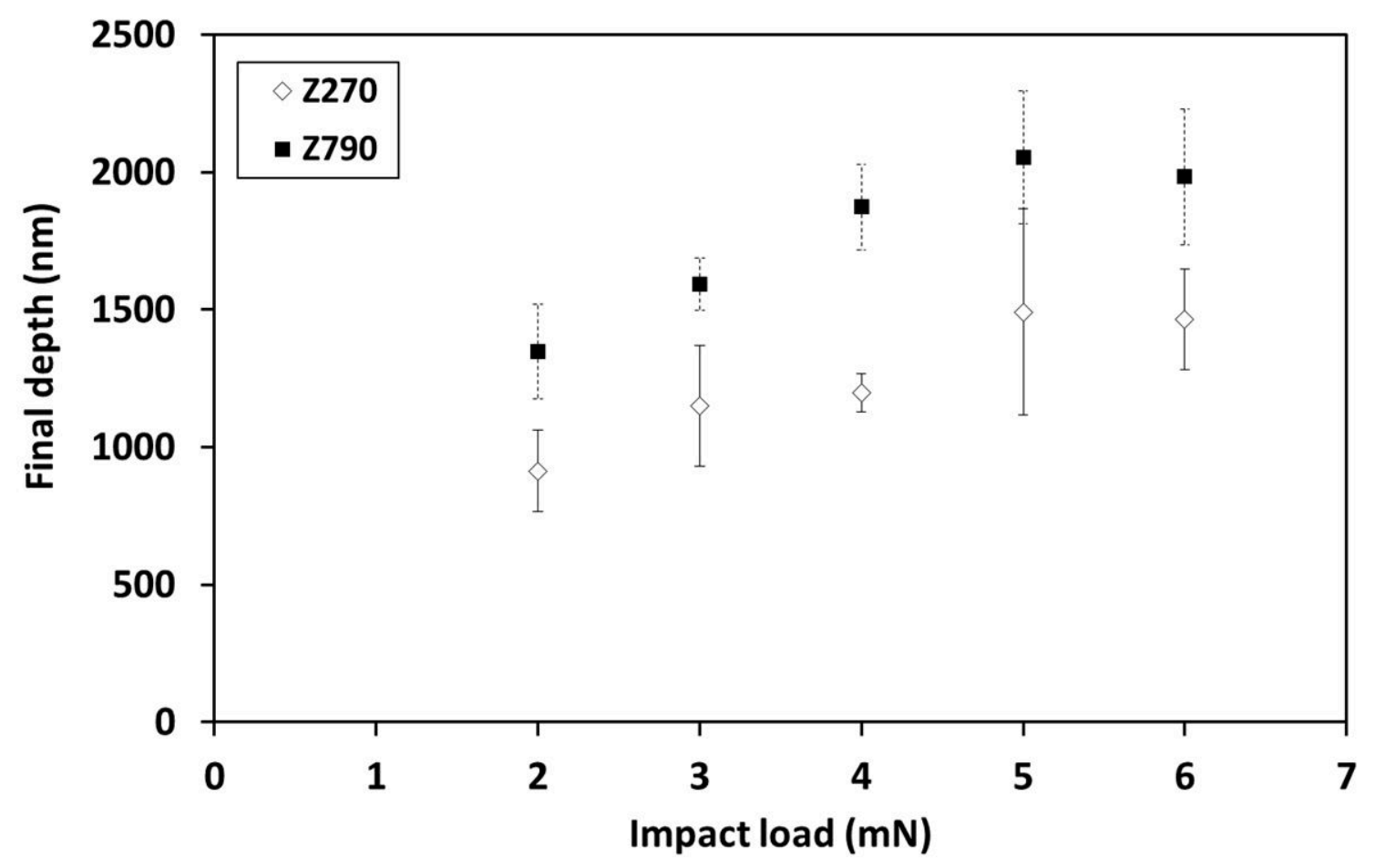

1(c) 

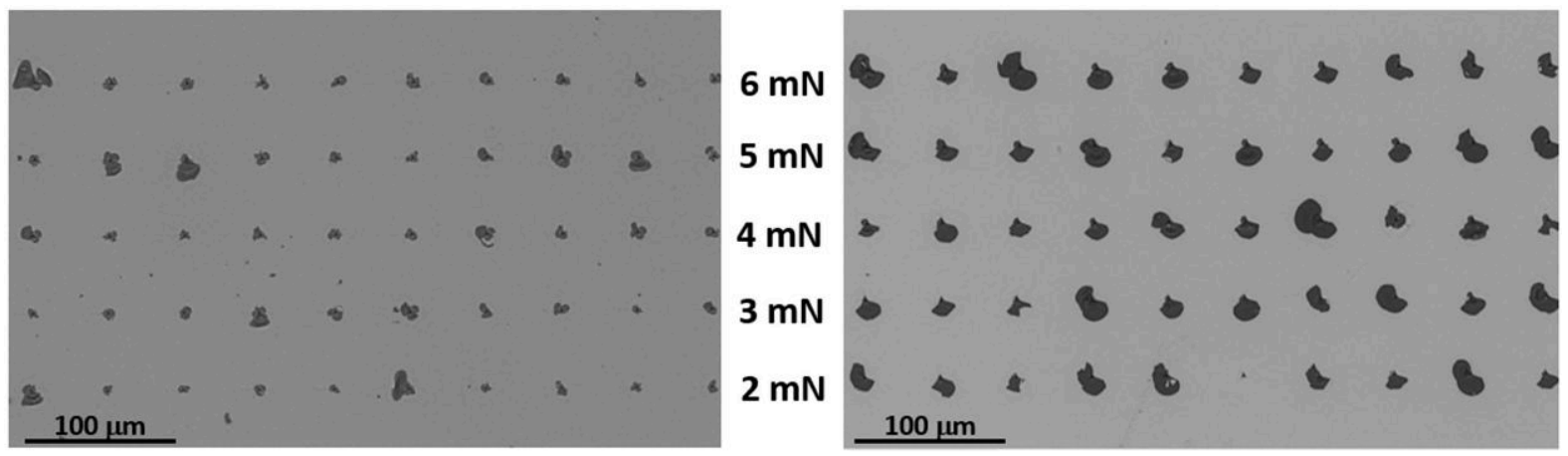

$1(\mathrm{~d})$

Figure 1. Nano-impact tests on $\mathrm{Z270}$ and $\mathrm{Z790}$ with a cube corner probe. Illustrative depth vs. impacts data on (a) Z270 and (b) Z790. (c) Load dependence of final impact depth. (d) BS SEM images of impacts on Z270 (left) and Z790 (right).

Illustrative results on Z270 and Z290 with the $4.8 \mu \mathrm{m}$ spherical probe are shown in figure 2 (a,b). A marked load dependence was observed for both samples. On Z790 the final impact depth was lower than the coating thickness at 1 and $2 \mathrm{mN}$. On Z270, the film was initially resistant to impact but by the end of the test the depth was similar to the film thickness. At higher load typically the gradual increase in depth with continued impact was interspersed by occasional small decreases (e.g. as after 17 impacts at $5 \mathrm{mN}$ on $\mathrm{Z} 270$ (fig. 2(a)), or 8 impacts at $10 \mathrm{mN}$ on Z790, (fig. 2(b)). The extent of correlation between the delaminated area and the applied load and impact depth were investigated. Figure 2 (c,d) show the load dependence of the final depth and chipped area. For the loads $(5-20 \mathrm{mN})$ where clear delamination occurred the difference in final depth between Z270 and Z790 was (476 \pm 154$) \mathrm{nm}$. BS SEM images of impacts with the spheroconical probe are shown in fig. 2(e-g). SE and BS SEM images of a 2 $\mathrm{mN}$ impact on $\mathrm{Z} 290$ are shown in fig. 2(h). 


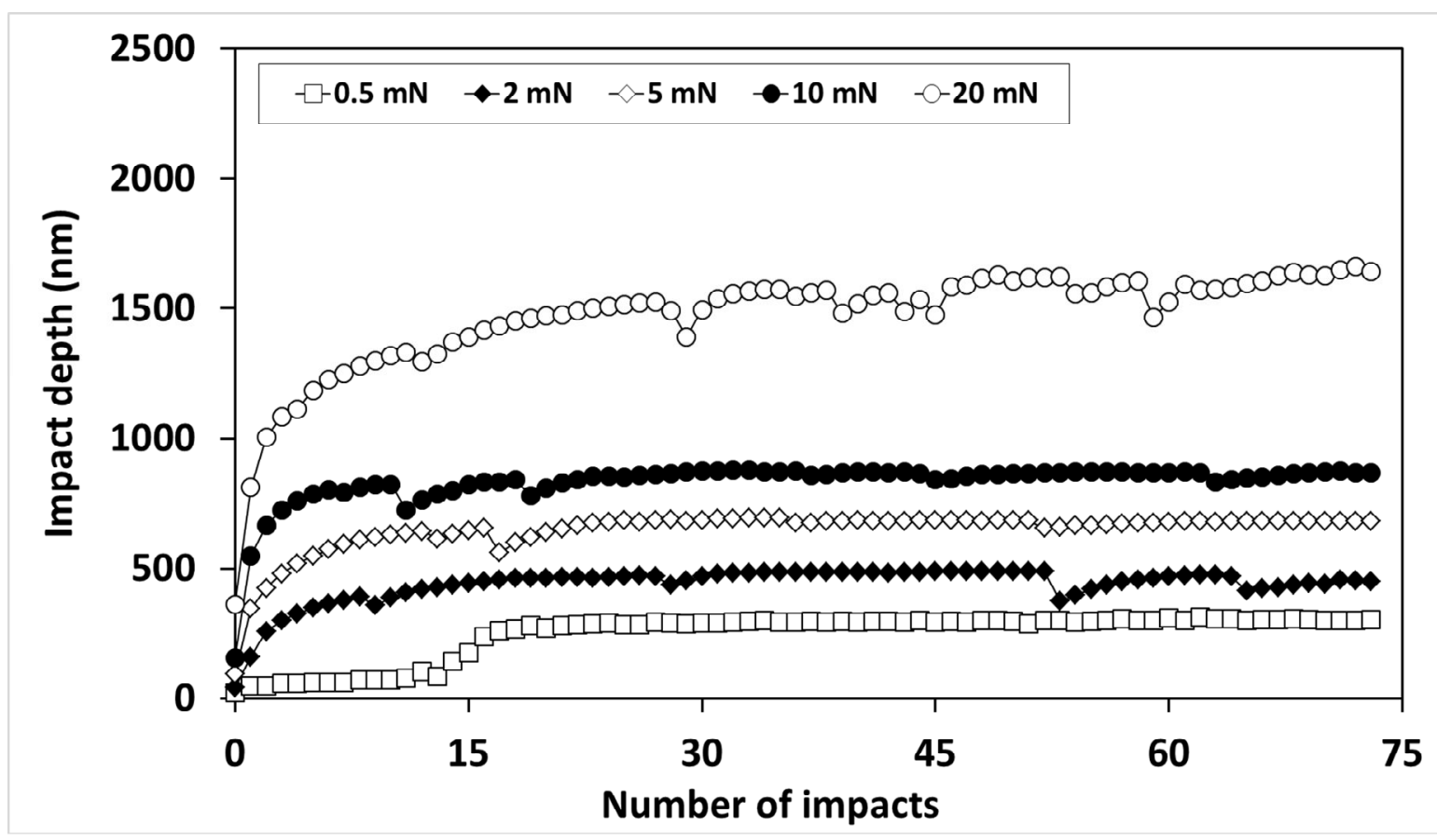

2 (a)

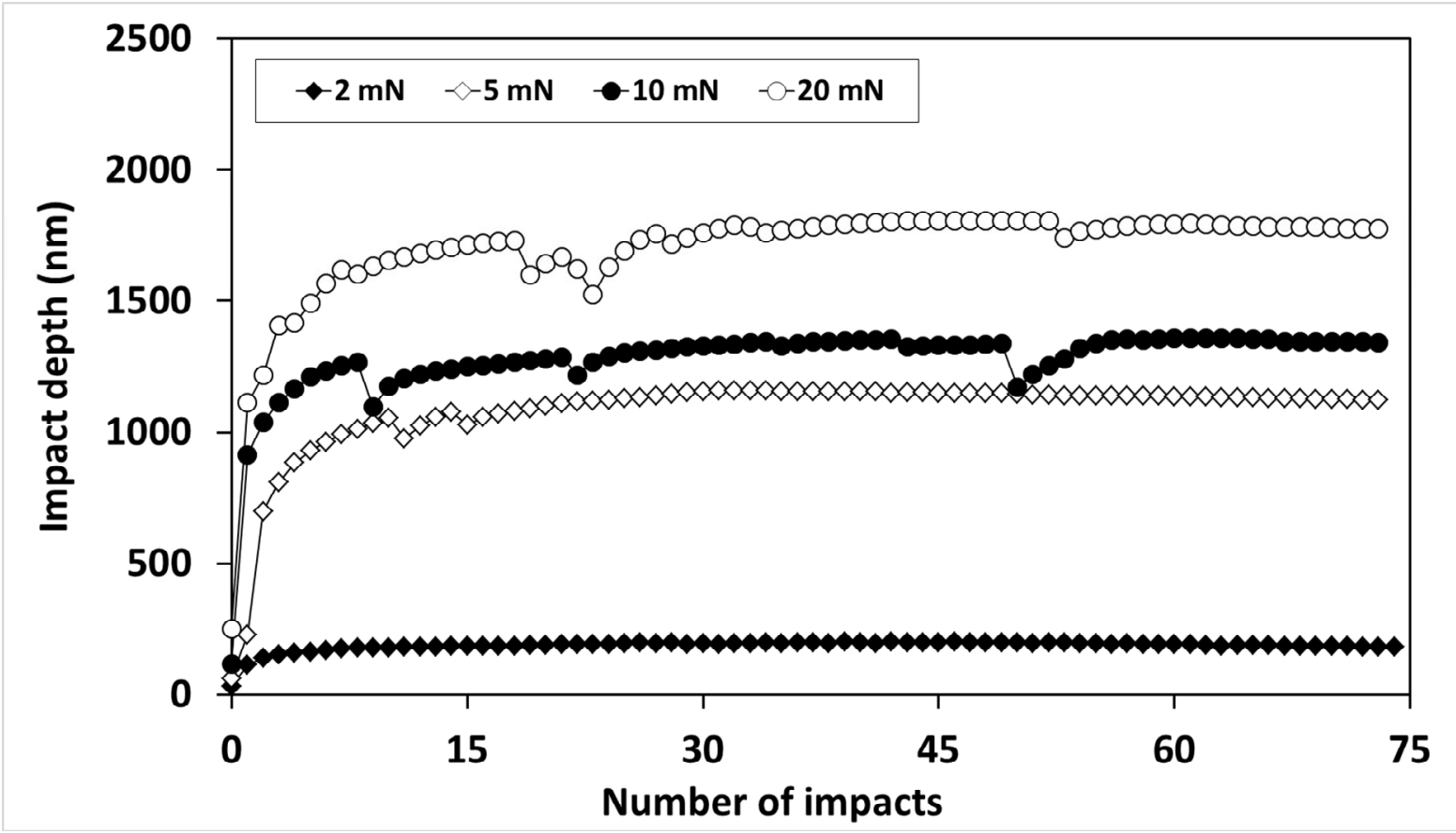

2 (b) 


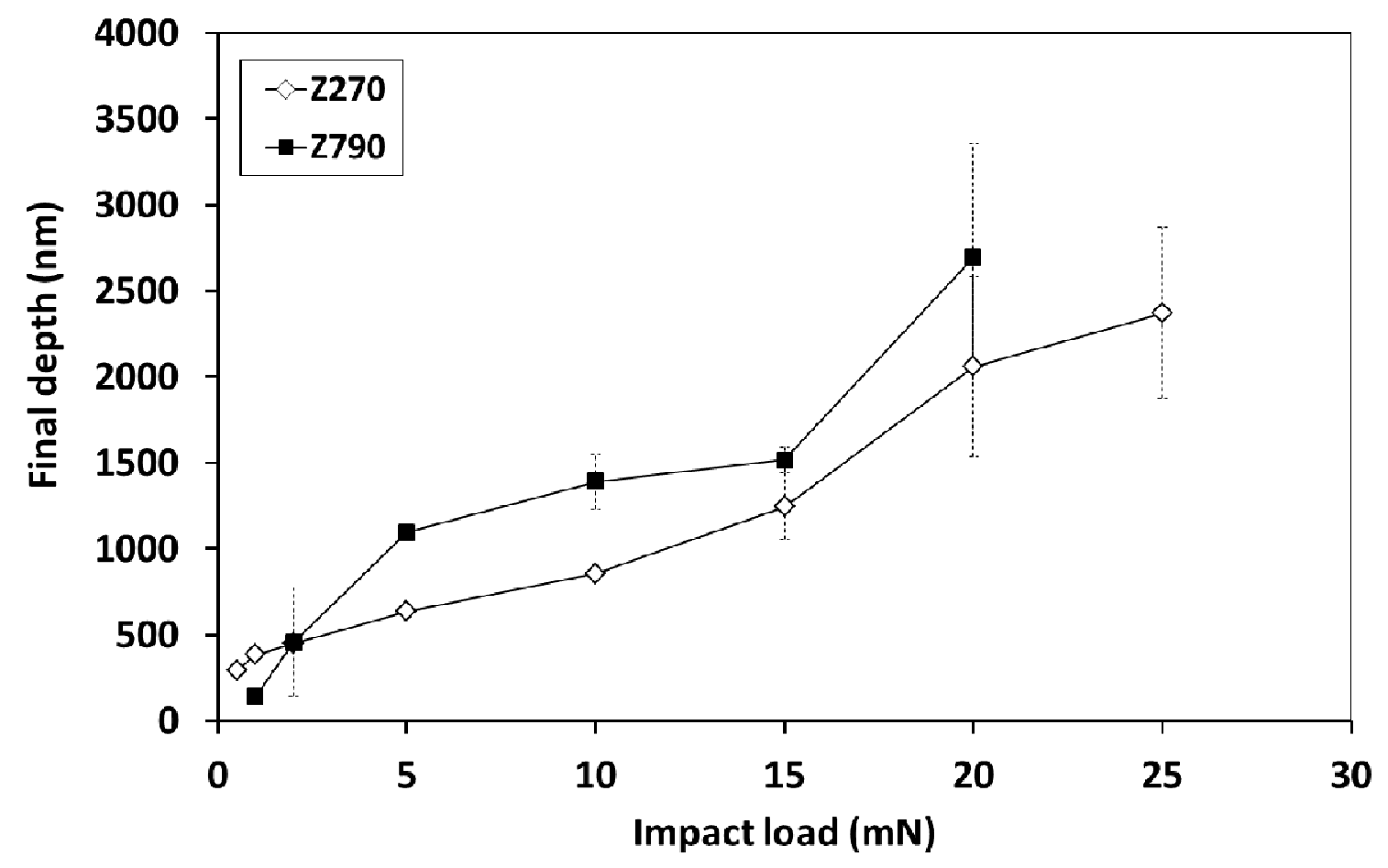

2 (c)

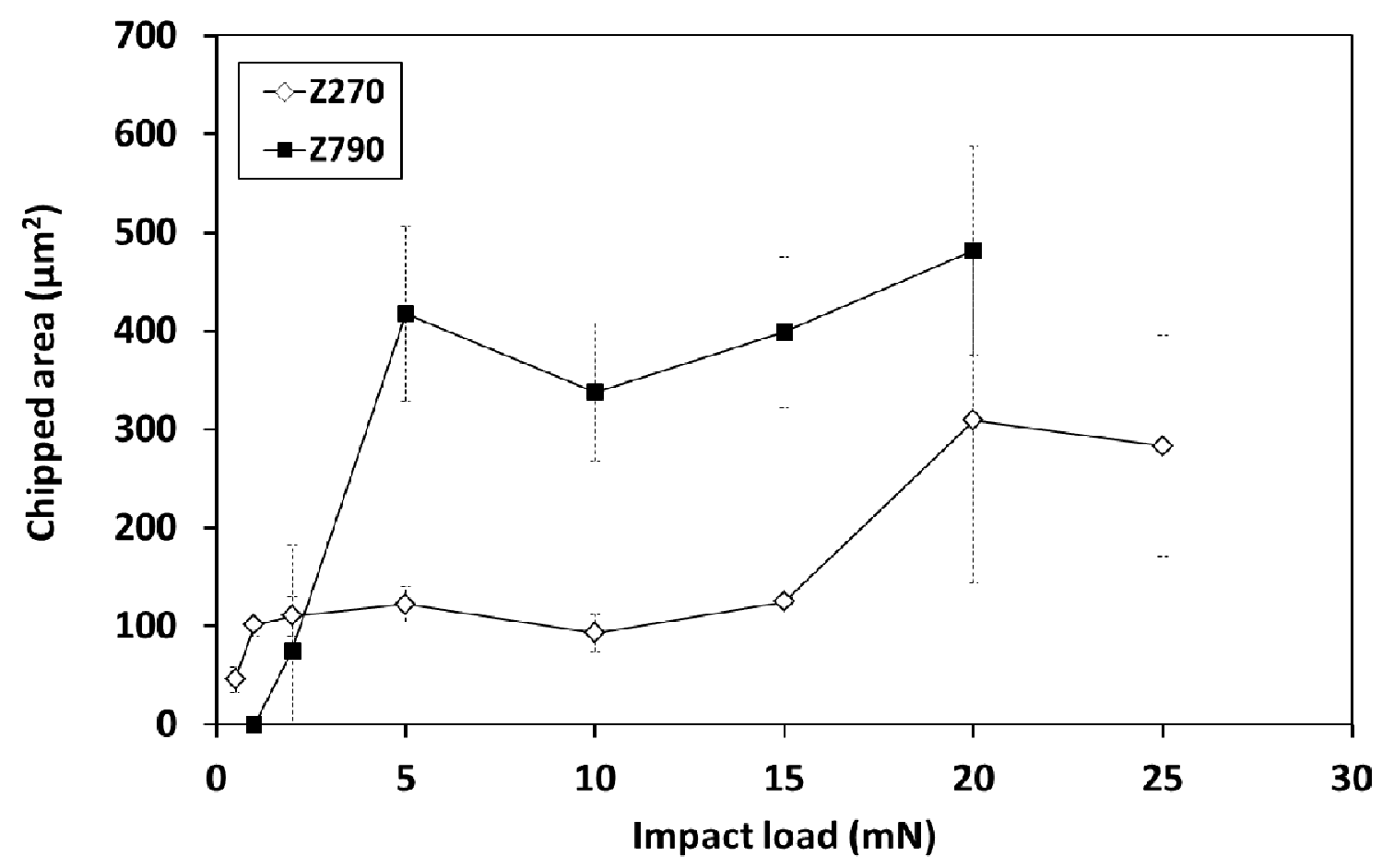

2(d) 


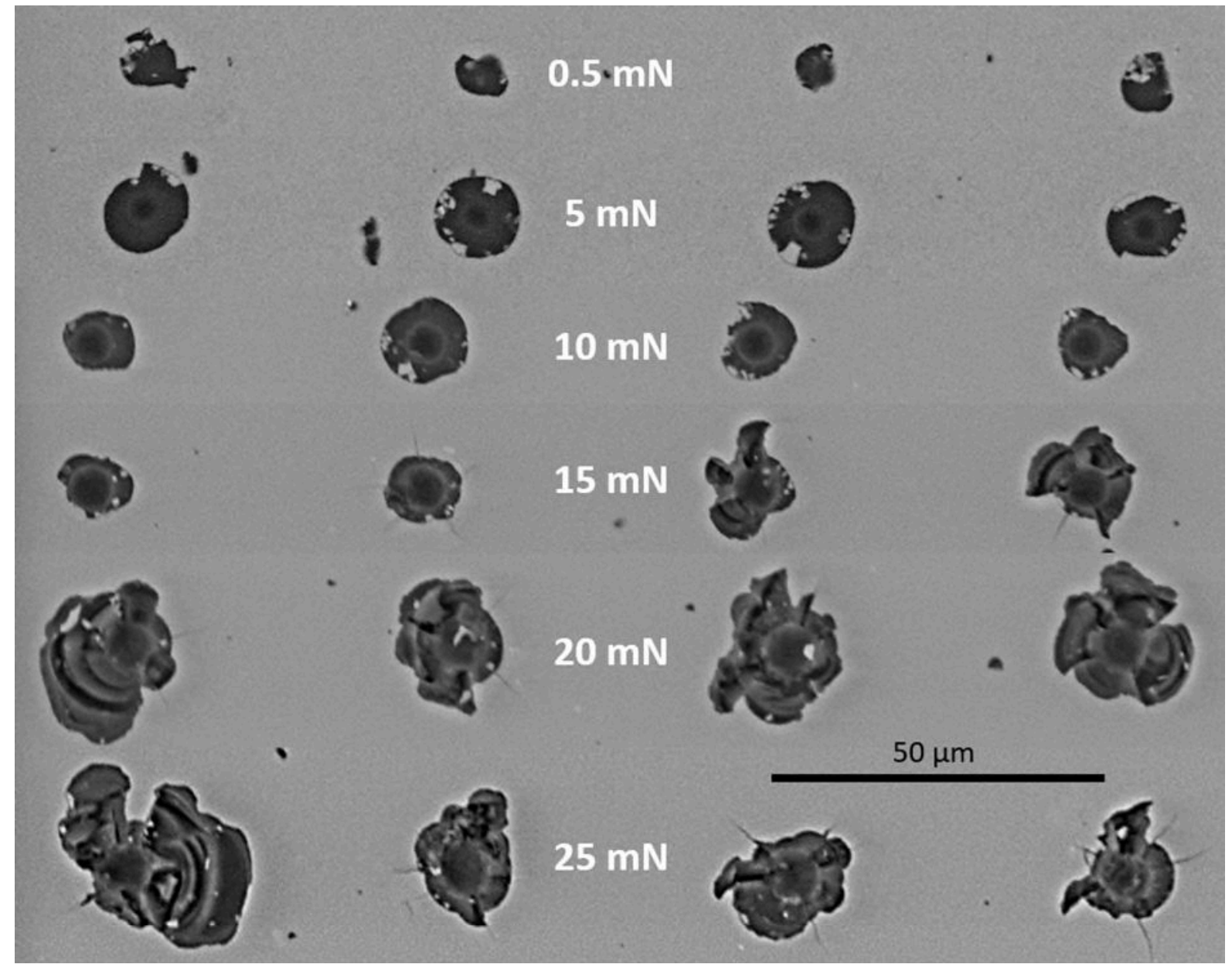

2 (e)
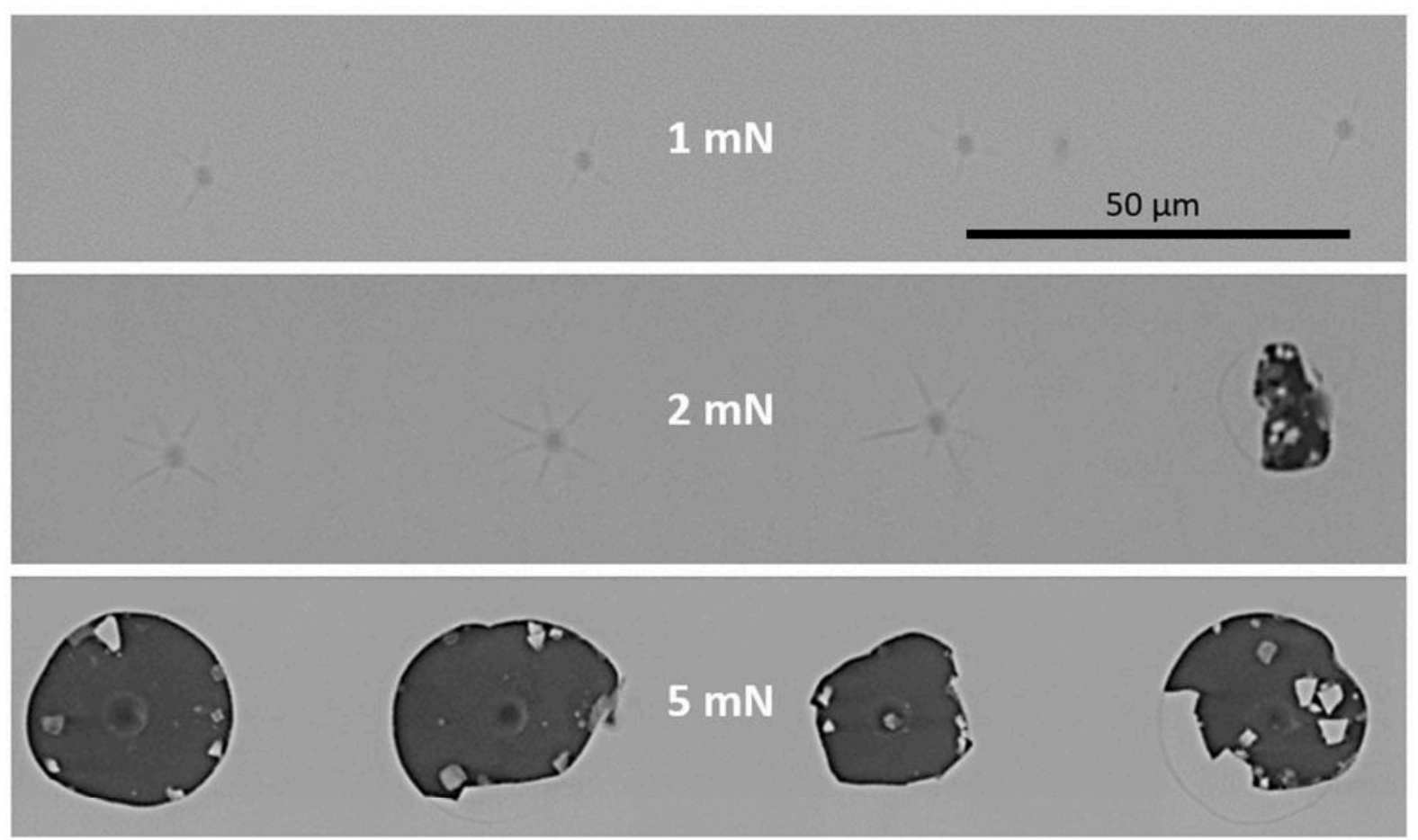

2 (f) 

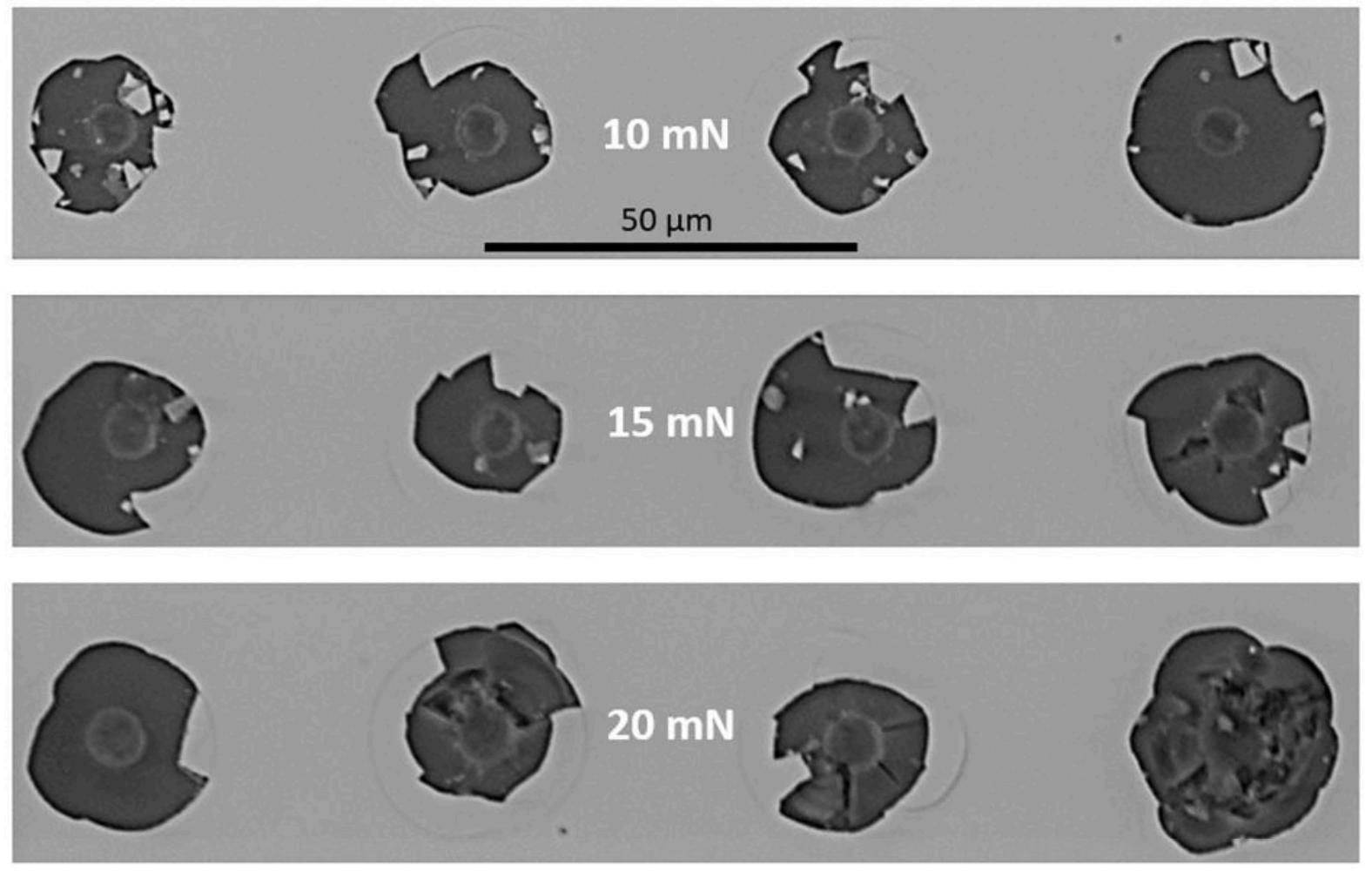

$2(\mathrm{~g})$
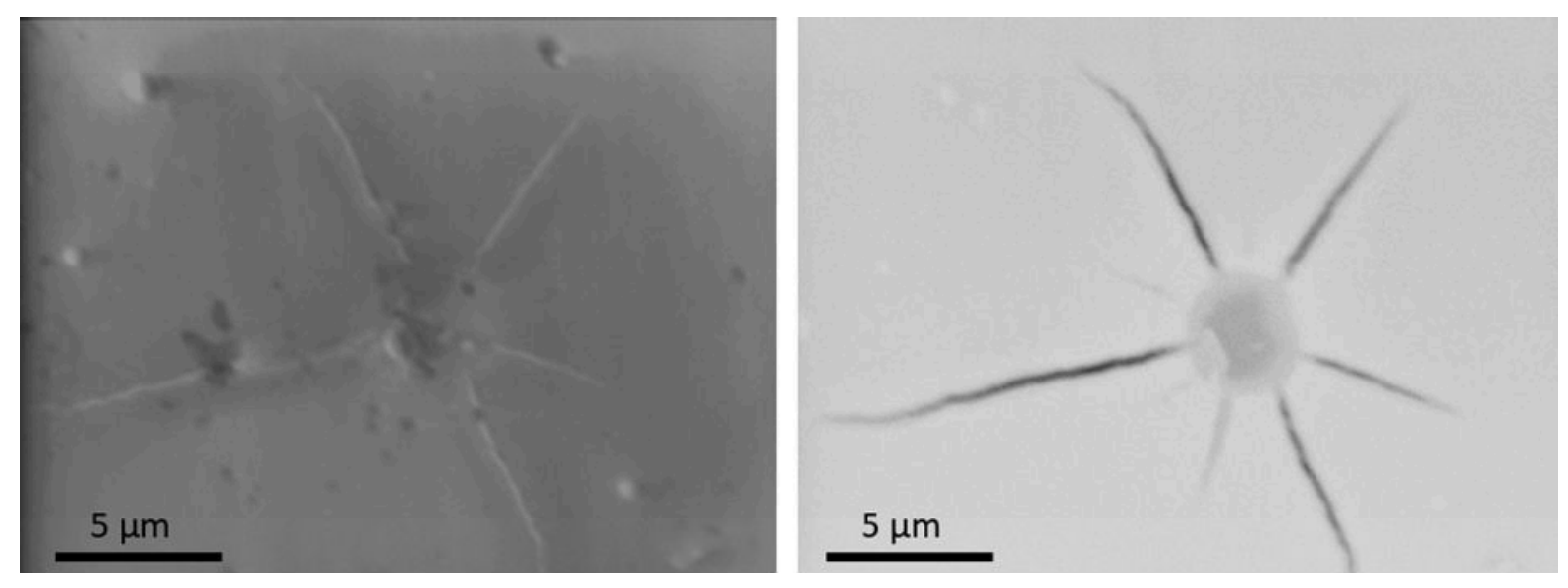

$2(\mathrm{~h})$

Figure 2. Nano-impact tests on $\mathrm{Z270}$ and $\mathrm{Z790}$ with $\mathrm{R}=4.8 \mu \mathrm{m}$ probe. Illustrative depth vs. impacts data on (a) Z270 and (b) Z790. (c) load dependence of the final depth (d) load dependence of chipped area (e) BS SEM images of impacts on Z270 (f) BS SEM images of impacts on Z790 at 1-5 mN (g) BS SEM images of impacts on Z790 at 10-20 mN (h) SE (left) and BS (right) SEM images of a $2 \mathrm{mN}$ impact on $\mathrm{Z290}$. 
Table 3 shows the depth after a single impact and at the end of the $600 \mathrm{~s}$ tests at $15 \mathrm{mN}$ with the $R=4.8 \mu \mathrm{m}$ probe. In these tests there was little difference in resistance to a single impact, with initial impact depth $h_{1} \sim 0.55 \mu \mathrm{m}$ for each sample. However, with continued impact differences emerged with the zirconia/alumina AZ145 and AZ170 being more damage tolerant and pure zirconia Z130 showing the best performance. Figure 3 (a) shows an optical microscopy image of the tests with the $4.8 \mu \mathrm{m}$ probe on AZ170. The variation of the final impact depth and chipped area with applied load is shown in Table 4. Similar load dependence was found for BS glass. At 10-20 $\mathrm{mN}$ the chipped area correlated reasonably well with the impact depth, with $R^{2}=0.83-0.96$, but the correlation breaks down at 25 and $30 \mathrm{mN}$ (fig. 3(b)).

\begin{tabular}{|c|c|c|}
\hline Sample ID & $h_{1}(\mu \mathrm{m})$ & $h_{f}(\mu \mathrm{m})$ \\
\hline Z130 & $0.61 \pm 0.04$ & $1.01 \pm 0.40$ \\
\hline AZ145 & $0.59 \pm 0.06$ & $2.17 \pm 0.95$ \\
\hline AZ170 & $0.57 \pm 0.06$ & $1.34 \pm 0.58$ \\
\hline A120 & $0.64 \pm 0.18$ & $2.47 \pm 0.61$ \\
\hline A130 & $0.52 \pm 0.04$ & $2.47 \pm 0.67$ \\
\hline BS glass & $0.58 \pm 0.11$ & $2.38 \pm 0.91$ \\
\hline
\end{tabular}

Table 3. Initial and final impact depths in $600 \mathrm{~s}$ nano-impact tests with $R=4.8 \mu \mathrm{m}$ probe at $15 \mathrm{mN}$.

\begin{tabular}{|c|c|c|}
\hline Applied load $(\mathrm{mN})$ & Final depth $(\mu \mathrm{m})$ & Chipped area $\left(\mu \mathrm{m}^{2}\right)$ \\
\hline 10 & $0.9 \pm 0.3$ & $84 \pm 66$ \\
\hline 15 & $1.3 \pm 0.6$ & $208 \pm 159$ \\
\hline
\end{tabular}




\begin{tabular}{|c|c|c|}
\hline 20 & $2.1 \pm 0.8$ & $344 \pm 277$ \\
\hline 25 & $3.4 \pm 1.0$ & $538 \pm 328$ \\
\hline 30 & $4.1 \pm 0.8$ & $645 \pm 165$ \\
\hline
\end{tabular}

Table 4. AZ170. Load dependence of final impact depths and chipped area in $600 \mathrm{~s}$ nanoimpact tests with $R=4.8 \mu \mathrm{m}$ probe.

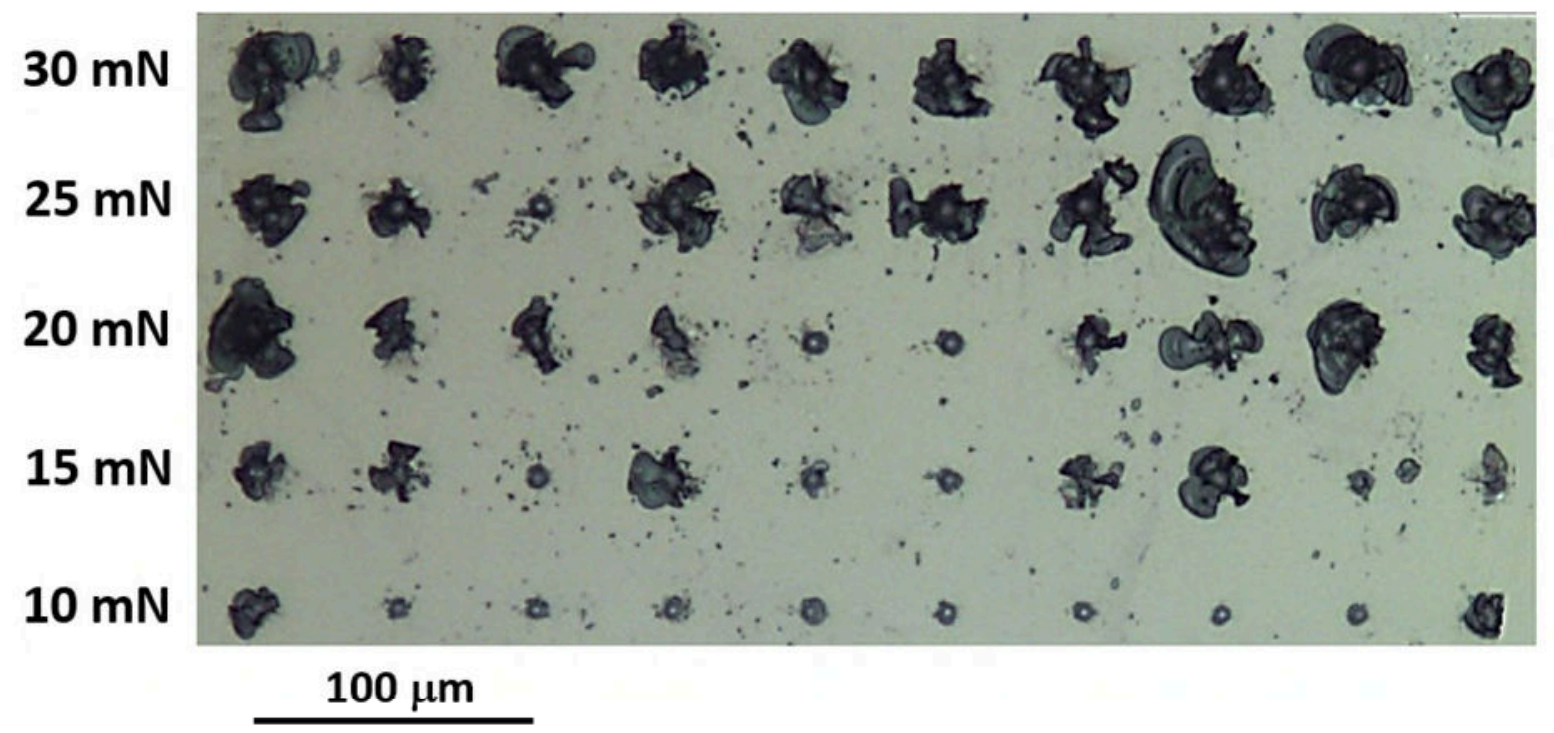

$3(\mathrm{a})$ 


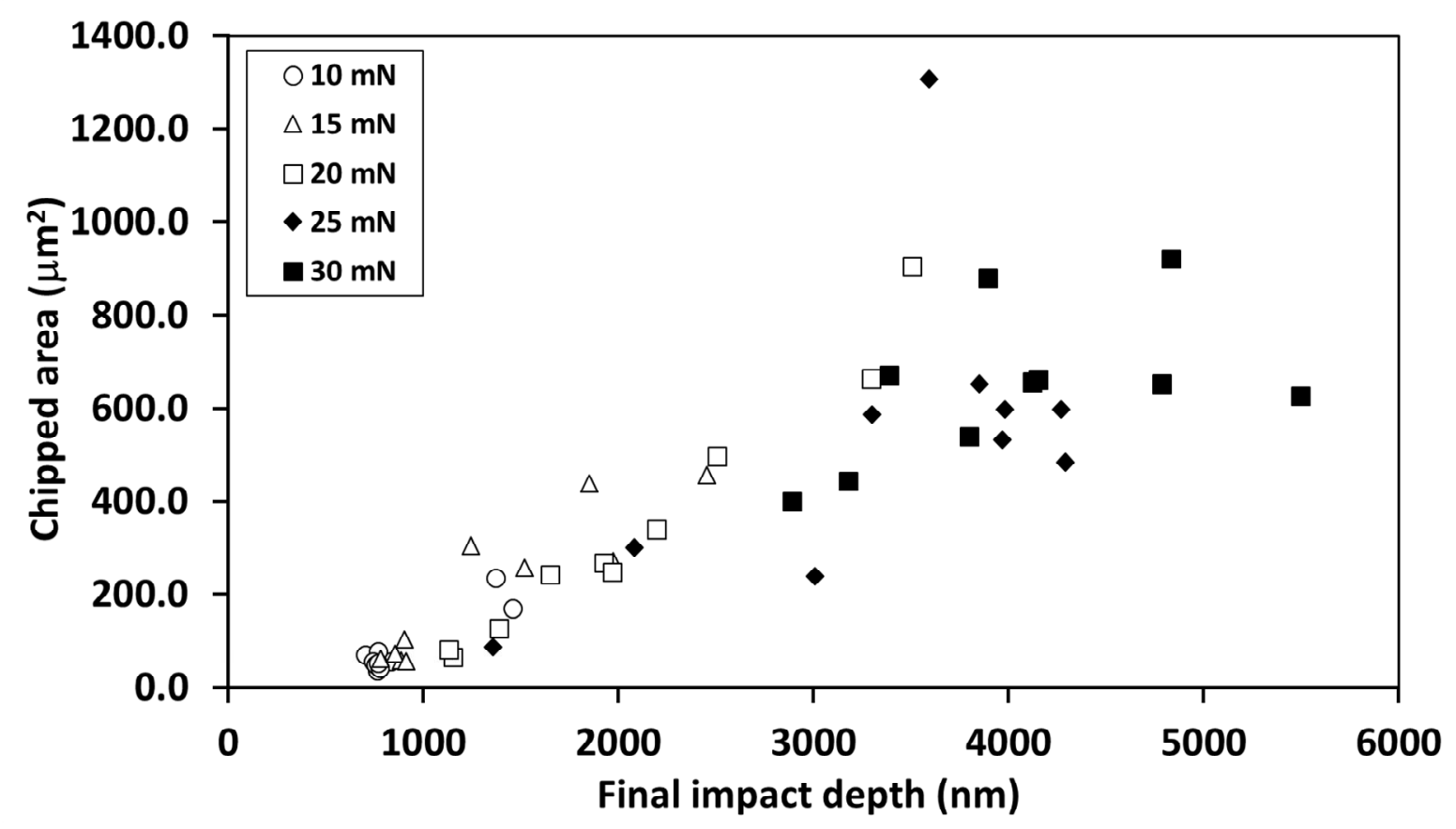

$3(b)$

Figure 3. Nano-impact tests on AZ170 with $R=4.8 \mu$ m probe. (a) Optical microscopy image of the tests. (b) Relationship between chipped area and impact depth.

Micro-impact tests were carried out on the three coatings that performed best in the $600 \mathrm{~s}$ nanoimpact tests. Plots of depth vs. number of impacts in micro-impact tests at 4,5 and $6 \mathrm{~N}$ on AZ170 are shown in figure 4 (a). There was greater elastic deformation on initial impact with the large radius probe, with initial depths of $\sim 4.4 \mu \mathrm{m}$ at $4 \mathrm{~N}$ increasing to $\sim 6.3 \mu \mathrm{m}$ at $6 \mathrm{~N}$. To more clearly observe differences in impact depth evolution the data can be converted to impact depth increases (i.e. by setting the depth after the first impact to zero, and graphically showing all subsequent impact depths relative to this). Figure 4 (b) shows the increase in depth after the first impact for tests at $5 \mathrm{~N}$. Comparative data at $6 \mathrm{~N}$ are shown in fig. 4(c). AZ145 was least resistant to repetitive impact at both loads. $6 \mathrm{~N}$ marks the onset of a more dramatic substrate failure, with significant damage occurring almost immediately on AZ145 and more marked depth increases after $\sim 30$ impacts for all three coated samples. 


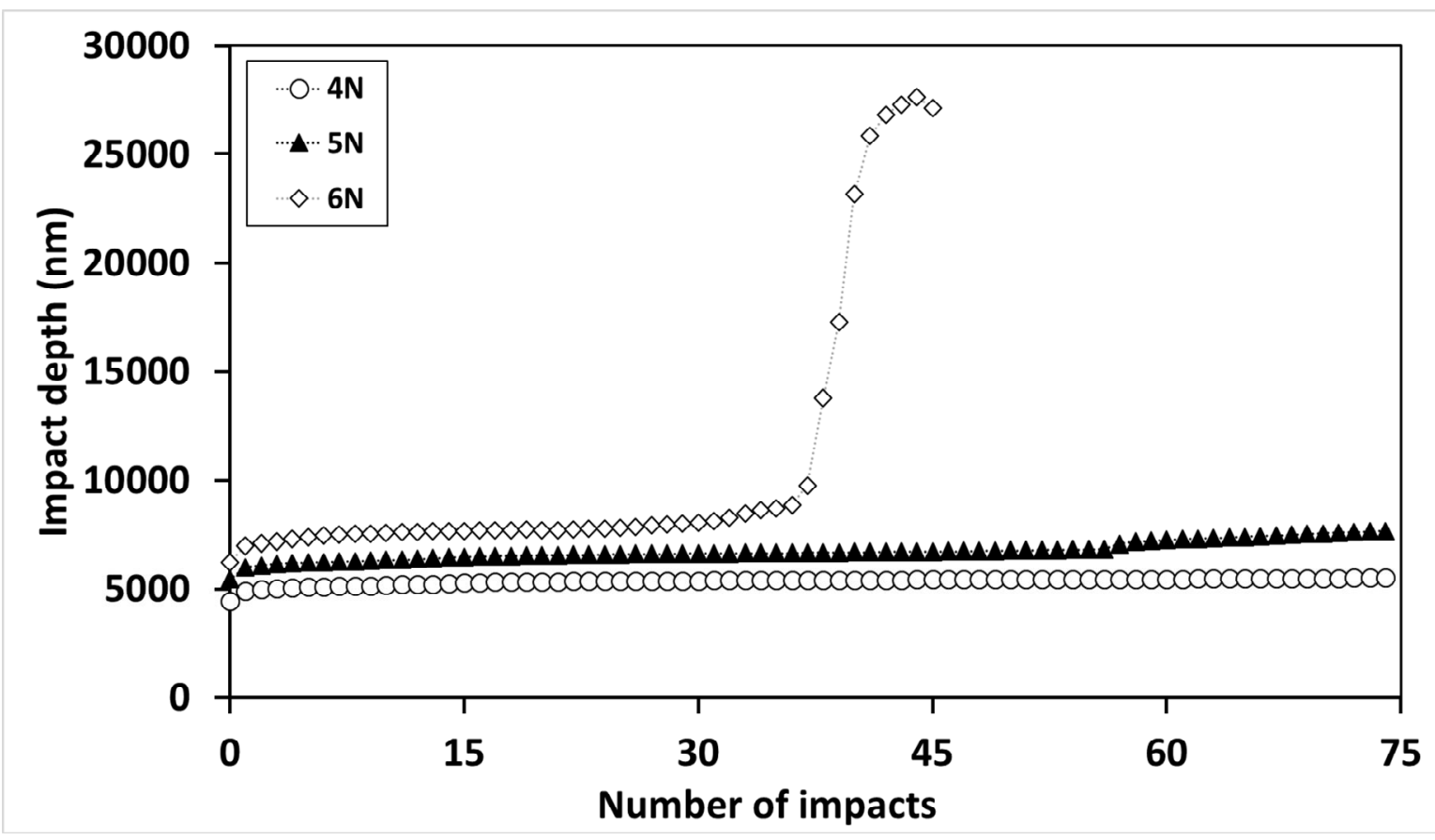

4. (a)

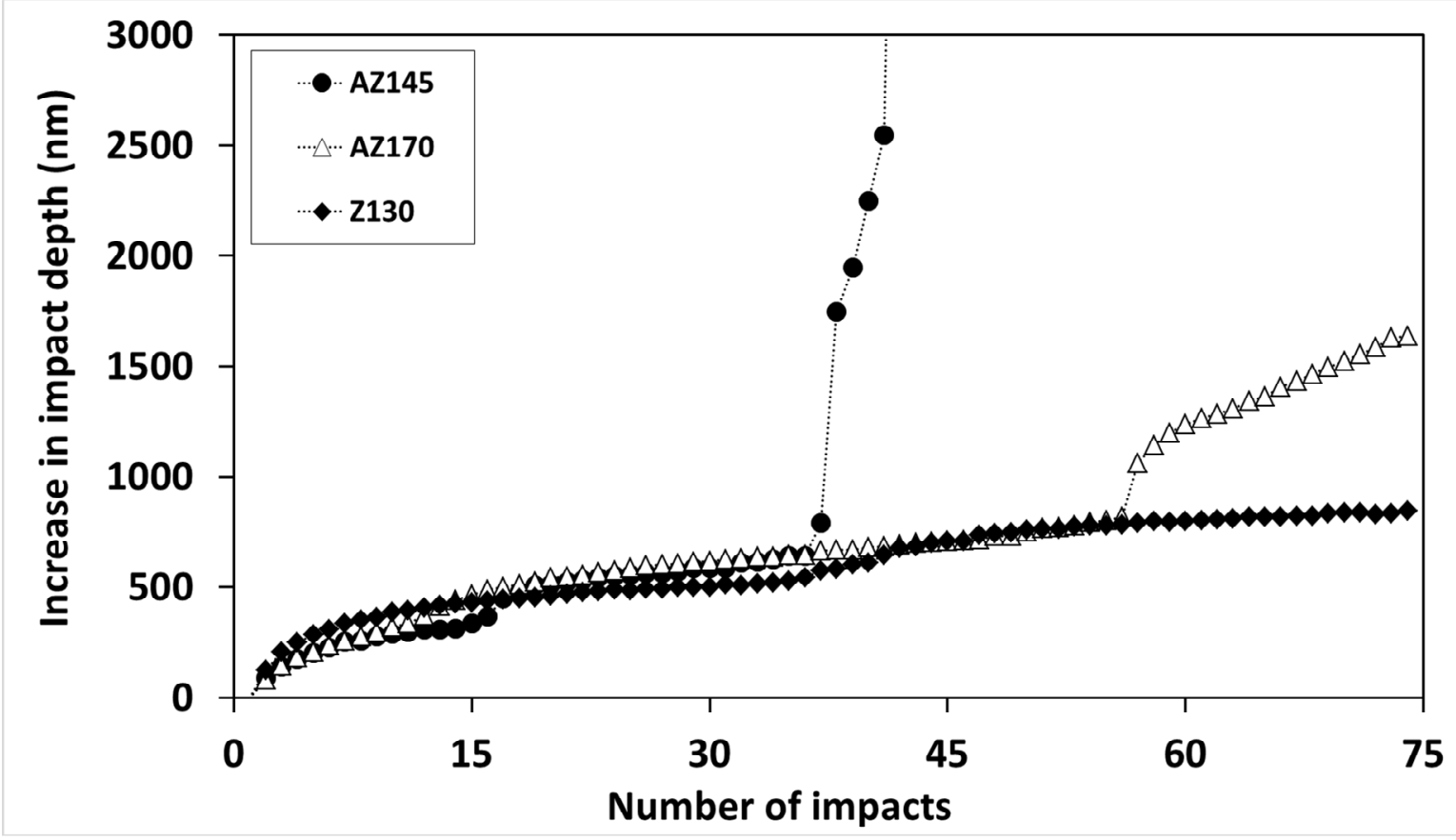

4 (b) 


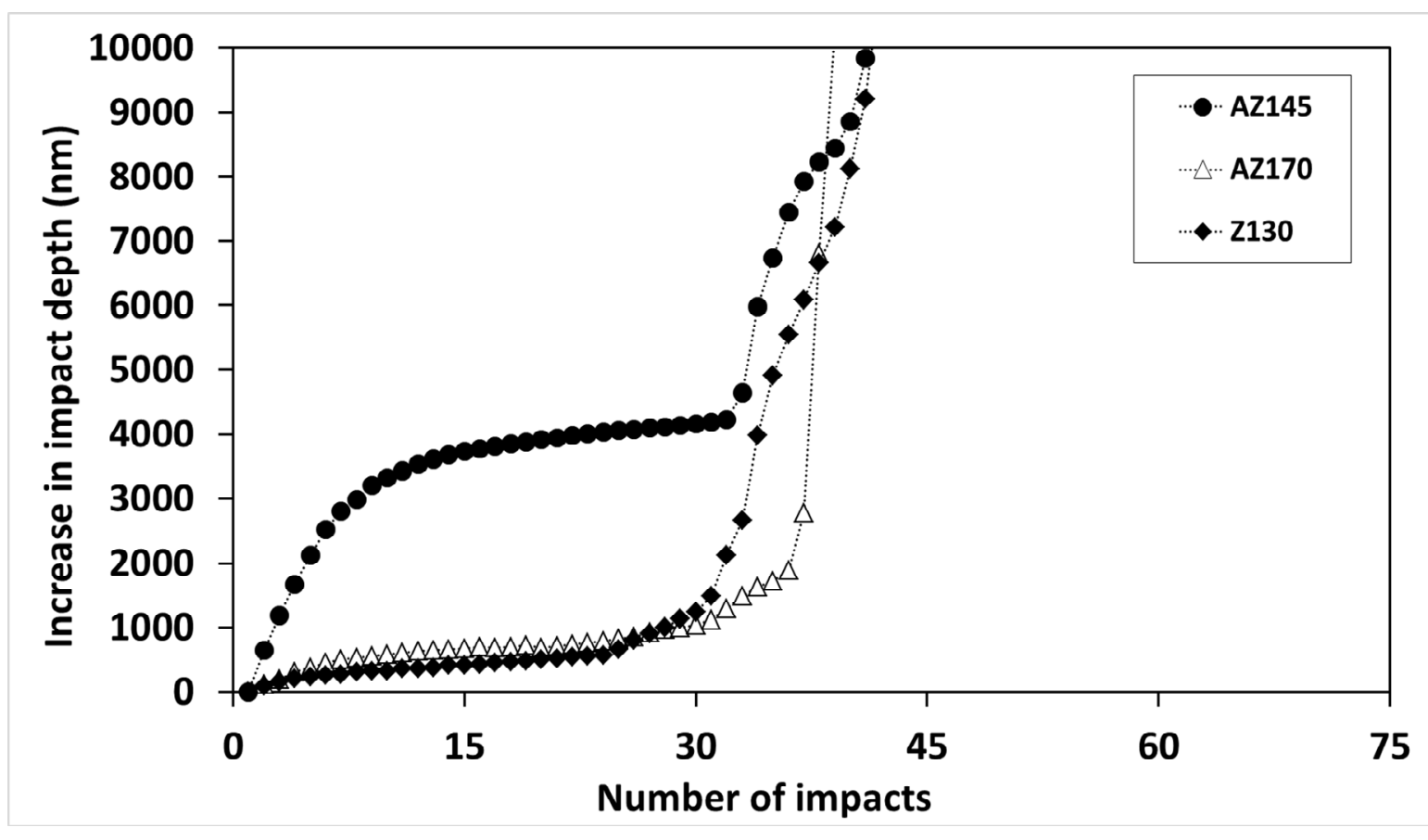

4 (c)

Figure 4. Micro-impact tests on Z130, AZ145, AZ170, with $R=100 \mu \mathrm{m}$ probe. (a) Depth vs. impacts data in 4, 5 and $6 \mathrm{~N}$ tests on AZ170 (b) Depth increases during tests at $5 \mathrm{~N}$. (c) Depth increases during tests at $6 \mathrm{~N}$.

\section{Discussion}

The deposition of zirconia, zirconia-alumina and alumina at low temperature resulted in predominantly amorphous films with not particularly high hardness. The alumina films produced with ion assistance were harder and stiffer than the borosilicate glass. The mechanical properties of the zirconia and zirconia-alumina coatings were very similar to the soda lime glass substrate. Although this minimised stress discontinuities at the coating-substrate interface, clear interfacial failures were observed in nano-impact and nano-scratch tests.

With the cube corner indenter, the initial impact depth on Z270 significantly exceeded the film thickness indicating that film fracture occurs on the first impact. Several impacts were required for an abrupt displacement increase (fracture) on the thicker film, but ultimately this led to 
larger final impact depth and chipped area. The mean difference in final impact depth, $(527 \pm$ 99) $\mathrm{nm}$, is close to the difference in thickness $520 \mathrm{~nm}$ between $\mathrm{Z} 270$ and $\mathrm{Z790} \mathrm{nm}$.

The $4.8 \mu \mathrm{m}$ radius spherical indenter proved more suitable for impact testing of these brittle coatings. The spherical geometry produced more gradual displacement increases than the sharper cube corner indenter (compare figs 1 (b) and 2 (b)), consistent with what has been reported previously in tests on hard coatings [6]. Tarres and co-workers reported that by switching from sharp to blunter spherical indenters increased the intrinsic test suitability for examining damage evolution in bulk materials as a function of number of cycles [17]. In contrast to the cube corner tests where film failure occurred in all but one of the 200 tests on $\mathrm{Z} 270$ and Z790 irrespective of the test load, with the $R=4.8 \mu \mathrm{m}$ probe it was possible to observe marked load dependence in the behaviour. At the lowest load the coatings were able to protect the glass substrate, but at higher load a transition occurred where coating and substrate failure was observed (between 2 and $5 \mathrm{mN}$ on Z790). As with the cube corner indenter, at $\geq 5 \mathrm{mN}$ the mean difference in final impact depth with the $4.8 \mu \mathrm{m}$ spherical indenter was also close to the difference in thickness between Z270 and Z790 nm.

The BS SEM imaging revealed main load dependent deformation mechanisms which were (i) radial cracking without chipping/delamination (ii) concentric ring cracks leading to chipping/delamination (iii) chipping/delamination accompanied by spiral cracking outside the chipped/delaminated region (iv) chipping/delamination accompanied by substrate fracture. It seems probable that circumferential cracks also formed at low load though these are not clear in the imaging (figure 2(h)). The BS images (fig. 2(f)) clearly show that the marked change between 2 and $5 \mathrm{mN}$ on $\mathrm{Z790}$ with the spherical indenter is due to a change in the predominant deformation from radial cracking to delamination. The BS images also show the onset of substrate fracture at $20 \mathrm{mN}$ is responsible for the transition in the final depth vs. load data between 15 and $20 \mathrm{mN}$ on both these samples (fig.2(c)). The results are consistent with 
previous reports of the evolution of crack systems in spherical indentation and cyclic fatigue tests where circumferential cracking is commonly observed, with a transition to radial cracking and chipping at higher load/test duration $[1,6]$.

By performing nano-impact and nano-scratch testing on Z270 and Z790 with the same $R=4.8$ $\mu \mathrm{m}$ probe, it was possible to investigate similarities and differences between the deformation behaviour in both types of test independent of any probe radius effects. During the nano-impact tests, isolated depth decreases of around $\sim 70 \mathrm{~nm}$ were observed (e.g. after 16 impacts at $5 \mathrm{mN}$ on Z270). Since download steps of $\sim 60-80 \mathrm{~nm}$ were also observed on the onset of fracture of the substrate in the nano-scratch tests, the same failure process may be occurring in both types of test. In the scratch test, the downward steps occurred at $190-200 \mathrm{mN}$ whilst steps were observed at similar depths in the repetitive impact tests at 20-25 $\mathrm{mN}$ and also at lower depth in tests at lower forces $(2-5 \mathrm{mN})$. Small depth decreases have been observed during micro-impact tests on coatings on cemented carbide and often mark the transition to a more rapid removal rate [6], but here are more likely to be associated with uplift / blistering due to cracking followed by material removal due to substrate fracture in both impact and scratch tests.

In an indentation test, the critical load for non-elastic deformation scales with the $H^{3} / E^{2}$ parameter, which is commonly taken as a measure of the resistance to plastic deformation. Increasing $H^{3} / E^{2}$ can therefore result in more elastic contact resulting in improved wear resistance at lower load [18-19], and improved resistance to fracture initiation. Nevertheless, to display enhanced resistance to crack propagation (i.e. damage tolerance), different properties may be required [20]. In this study, the data in Tables 2 and Table 3 show that the resistance of the coating-substrate systems with the highest $H^{3} / E^{2}$ to repetitive impact is inferior. The best impact resistance was shown by Z130 which has the lowest $H^{3} / E^{2}$ of all the systems studied. Although the reasons are not clear, it could more effectively dissipate energy through plastic deformation and/or micro-fracture processes to minimise strain accumulation. It has been noted 
previously that films with high $H^{3} / E^{2}$ and an additional structural advantage such as multilayering have improved impact resistance [21-22]. For the brittle amorphous coatings studied here, there is no associated structural benefit and the duplex coatings A145, A170 do not display as strong impact resistance as the monolayer Z130.

Although a smaller number of micro-impact tests were performed, these were sufficient to assess the general features of the deformation and determine the main similarities and differences from the deformation observed in nano-impact tests. In comparison to more commonly impact-tested harder PVD coatings on tougher substrates, the higher brittleness of the optical coatings requires different probe geometries to be used. When testing hard and tough coatings cube corner indenters for nano-impact and $\mathrm{R}=25 \mu \mathrm{m}$ probes for micro-impact have proved effective and blunter probes that were necessary for the optical coatings on glass are typically not able to induce fracture. The energy supplied per impact is the product of the impact load and accelerating distance (AD) [23]. The energy supplied at $5 \mathrm{~N}$ and $\mathrm{AD}=25 \mu \mathrm{m}$ was over $\mathrm{x} 500$ greater than in the nano-impact tests at $15 \mathrm{mN}$ and $\mathrm{AD}=15 \mu \mathrm{m}$. For the spherical probes used in this study, with radii of 5 and $100 \mu \mathrm{m}$, this resulted in an initial (predominantly elastic) impact depth $\sim$ x10 greater. Despite this difference, by converting raw impact data to impact depth increases during the test (i.e. setting the depth after a single impact to zero to remove the influence of load-dependent elastic deformation, and graphically showing all subsequent impact depth data relative to this), enabled the cycle-by-cycle response to multiple micro-impact with a blunt $100 \mu \mathrm{m}$ probe to be directly compared that observed in nano-impact tests with a much sharper spherical probe. This is illustrated by tests on AZ170 shown in figure 5. The figure shows that the increase in impact depth during the first 30 impacts for tests at $4-6 \mathrm{~N}$ with the $100 \mu \mathrm{m}$ probe and at $15-25 \mathrm{mN}$ with the $4.8 \mu \mathrm{m}$ probe. An inflexion in the micro-impact data occurs due to coating failure, after 14 impacts at $4 \mathrm{~N}, 12$ impacts at 5 $\mathrm{N}$ and $\sim 4$ impacts at $6 \mathrm{~N}$. Similar inflexions were also observed in the nano-impact data, with 
the transitions to faster damage rates being preceded by small depth decreases on this sample. The AZ145 coating was more susceptible to substrate fracture in nano- and micro- tests than the AZ170 and Z130 coatings tested under the same conditions. Lawn and co-workers have reported that the deformation in an indentation contact is a function of the radius of the indenter, with larger radii indenters producing more brittle deformation and smaller radii indenters more plasticity [24]. Large-scale substrate fracture was observed in the micro-impact tests at $6 \mathrm{~N}$ but was not observed in the nano-impact tests with the sharper probe, at least within the range of forces studied.

When comparing coatings and their deformation mechanisms across wide force ranges and/or different probe geometries, small inflexions in the probe depth that correspond to failure events may be obscured when data are plotted together. The novel approach (setting $h=0$ after the first impact) enables (i) comparison of nano- and micro-impact data with different probe geometries and (ii) convenient investigation of load-dependent behaviour at either length scale whilst keeping the same probe geometry.

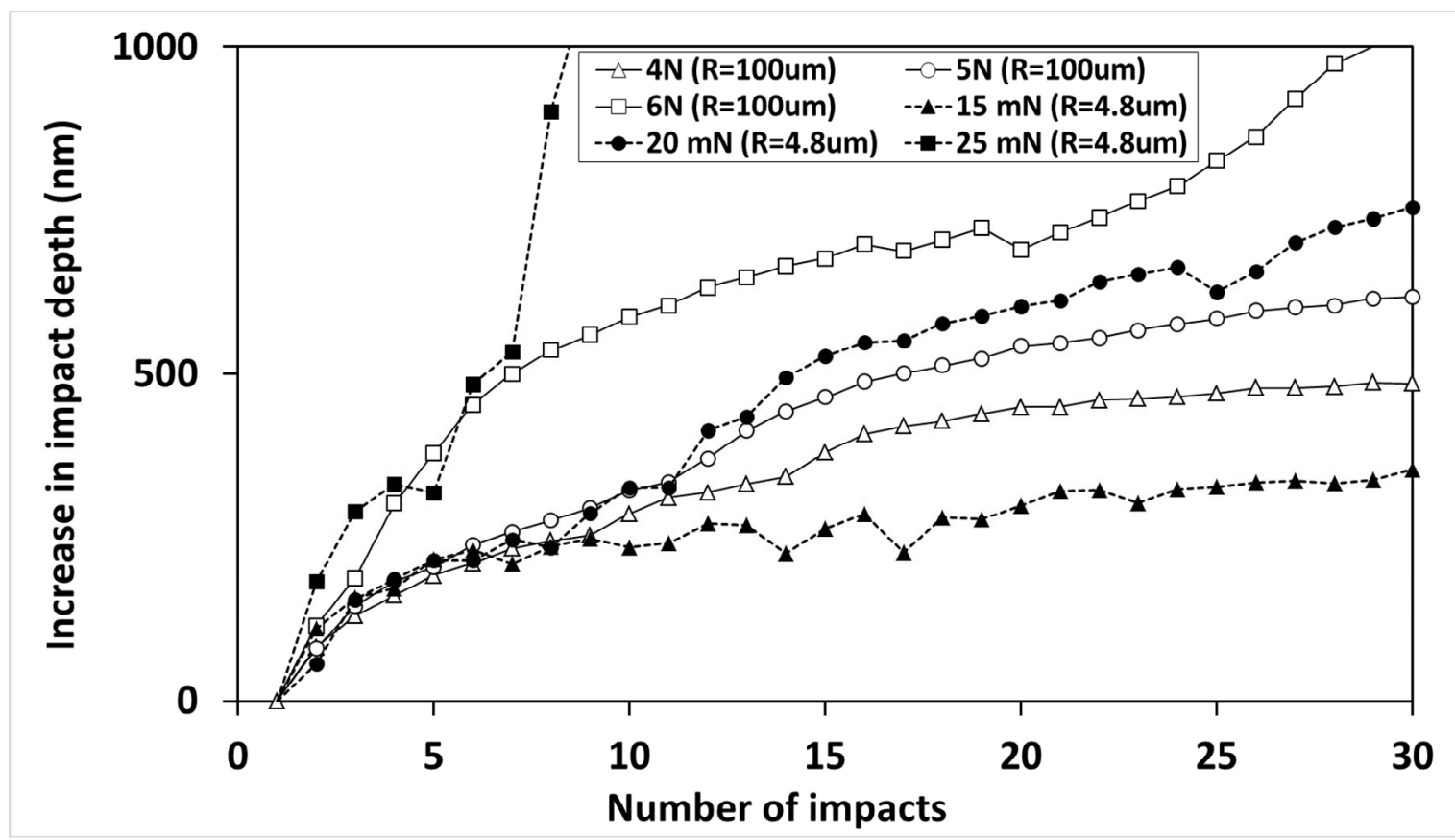


5.

Figure 5. Comparison between nano- and micro-impact tests on AZ170. Tests at 4-6 N and $A D=25 \mu \mathrm{m}$ with $100 \mu \mathrm{m}$ probe and at $15-25 \mathrm{mN}$ and $\mathrm{AD}=15 \mu \mathrm{m}$ with $4.8 \mu \mathrm{m}$ probe.

\section{Conclusions}

Spheroconical probes were found to be more suitable to study the load sensitivity of the impact response than sharp cube corner indenters. Increased resistance to plastic deformation in the system (higher $H^{3} / E^{2}$ ) proved detrimental to the resistance to the repetitive impact in nano- and micro-impact tests. Despite the $\sim$ x500 difference in impact energy in nano- and micro-impact tests, the relative ranking of coating performance in both regimes was consistent, with the thinner alumina-zirconia duplex coating (AZ145) more susceptible to substrate fracture in nano- and micro-scale tests. This could be due to the underlay (alumina) being half the thickness of the thicker duplex coating (AZ170) coating. When comparing coatings and their deformation mechanisms across wide force ranges and/or different probe geometries, small inflexions in the probe depth that correspond to failure events may be obscured. A novel conversion of the data to depth increases (i.e. setting $h_{1}=0$ ) has been used to show that the damage evolution can follow similar trends with number of impacts in both nano-scale and micro-scale impact tests. Nano-impact and nano-scratch tests performed using the same $R=$ $4.8 \mu \mathrm{m}$ spheroconical probe revealed similarities in deformation behaviour ascribed to cracking and blistering of the glass substrate.

\section{Acknowledgements}

Funding to develop the novel micro-impact test technique through the Innovate UK Project No: 132369 - "Nano-to Micro-Impact Testing: An in-situ test for UK SEAC sector" is 
gratefully acknowledged. J.L.E acknowledges the support provided by the Spanish Government (MINECO), Project SUSANA (ref. PID2019-108103RB-C31).

\section{References}

[1] D.K. Kim, Y.-G. Jung, L. M. Peterson, B.R. Lawn, Cyclic fatigue of intrinsically brittle ceramics in contact with spheres, Acta Mater. 47 (1999) 4711-4725.

[2] B.D. Beake, V.M. Vishnyakov, J.S. Colligon, Nano-impact testing of TiFeN and TiFeMoN films for dynamic toughness evaluation, J. Phys. D: Appl. Phys. 44 (2011) 085301.

[3] G. Constantinides, C.A., Tweedie, N. Savva, J.F. Smith, K.J. Van Vliet, Quantitative Impact Testing of Energy Dissipation at Surfaces. Experimental Mechanics, 2009. 49(4): p. 511-522. DOI: 10.1007/s11340-008-9198-1.

[4] J.M. Wheeler, A.G. Gunner, Analysis of failure modes under nano-impact fatigue of coatings via high-speed sampling. Surface \& Coatings Technology, 232 (2013) 264268.

[5] X. Zhang, S. Zhang, B.D. Beake, Toughness Evaluation of Thin Hard Coatings and Films, Chapter 2, pp48-121 in Thin Films and Coatings: Toughening and Toughness Characterisation, ed. S Zhang, CRC Press, July 2015.

[6] B.D. Beake, L. Isern, J.L. Endrino, G.S. Fox-Rabinovich, Micro-impact testing of AlTiN and TiAlCrN coatings, Wear 418-419 (2019) 102-110.

[7] B.D. Beake, T.W. Liskiewicz, A. Bird, X. Shi, Micro-scale impact testing - A new approach to studying fatigue resistance in hard carbon coatings, Tribol. Int., In press, available online 11 April 2019. 
[8] Q. Zhou, W. Han, Y. Du, H. Wu, A. Bird, X. Zhao, X. Wang, H. Wang, B.D. Beake, Enhancing fatigue wear resistance of a bulk metallic glass via introducing phase separation: A micro-impact test analysis, Wear 436-437 (2019) 203037 (9pp).

[9] N. Cinca, B.D. Beake, A.J. Harris, E. Tarrés, Micro-scale impact testing on cemented carbide, Int. J. Refract. Met. Hard Mater 84 (2019) 105045 (9pp).

[10] E. Tarrés, G. Ramírez, Y. Gaillard, E. Jiménez-Piqué and L. Llanes, Contact fatigue behaviour of PVD-coated hardmetals, Int. J. Refract. Met. Hard Mater. 27 (2009) 323341.

[11] L. Simurka, R. Ctvrtlik, T. Roch, T. Turutoglu, S. Erkan, J. Tomastik, K. Bange, Effect of deposition conditions on physical properties of sputtered silicon oxynitride thin films on float glass, Int. J. Appl. Glass Sci. 2018. DOI: 10.1111/ijag.12346.

[12] L. Šimurka, R. Čtvrtlík, J. Tomaštík, G. Bektaş, J. Svoboda, K. Bange, Mechanical and optical properties of $\mathrm{SiO} 2$ thin films deposited on glass, Chemical Papers, DOI: 10.1007/s11696-018-0420-z.

[13] A. Taylor, J. Drahokoupil, L. Fekete, L. Klimsa, J. Kopecek, A. Purkrt, Z. Remes, R. Ctvrtlik, J. Tomastik, O. Frank, P. Janicek, J. Mistrik, V. Mortet, Structural, optical and mechanical properties of thin diamond and silicon carbide layers grown by low pressure microwave linear antenna plasma enhance chemical vapour deposition, Diam. Relat. Mater. 69 (2016) 13-18.

[14] O. Borrero-López, M. Hoffman, A. Bendavid, P.J. Martin, Substrate effects on the mechanical properties and contact damage of diamond-like carbon thin films, Diam. Relat. Mater. 19 (2010) 1273-1280.

[15] O. Borrero-López, M. Hoffman, A. Bendavid, P.J. Martin, The use of the scratch test to measure the fracture strength of brittle thin films, Thin Solid Films 518 (2010) 4911-4917. 
[16] M. Weidner, O. Borrero-López, M. Hoffman, A. Bendavid, P.J. Martin, Effect of substrate roughness on the contact damage of thin brittle films on brittle substrates, Thin Solid Films 518 (2010) 5242-5248.

[17] E. Tarres, G. Ramirez, Y. Gaillard, E. Jimenez-Pique and L. Llanes, Contact fatigue behaviour of PVD-coated hardmetals, Int. J. Refract. Met. Hard Mater. 27 (2009) 323341.

[18] S. Hassani, M. Bielawski, W. Beres, L. Martinu, M. Balazinski and J.E. KlembergSapieha, Predictive tools for the design of erosion resistant coatings, Surf. Coat. Technol. 203 (2008) 204-210.

[19] S. Hassani, M. Bielawski, W. Beres, M. Balazinski, L. Martinu and J.E. KlembergSapieha, Impact stress absorption and load spreading in multi-layered erosionresistant coatings, Wear 268 (2010) 770-779.

[20] E. Bousser, M. Benkahoul, L. Martinu and J.E. Klemberg-Sapieha, Effect of microstructure on the erosion resistance of Cr-Si-N coatings, Surf. Coat. Technol. 203 (2008) 776-780.

[21] G.S. Fox-Rabinovich, B.D. Beake, K. Yamamoto, M.H. Aguirre, S.C. Veldhuis, G. Dosbaeva, A. Elfizy, A. Biksa, and L.S. Shuster, A.Y. Rashkovskiy, Structure, properties and wear performance of nano-multilayered TiAlCrSiYN/TiAlCrN coatings during machining of Ni-based aerospace superalloys, Surf Coat Technol 204 (2010) 3698-3706.

[22] G.S. Fox-Rabinovich, K. Yamamoto, B.D. Beake, A.I. Kovalev, M.H. Aguirre, S.C. Veldhuis, G.K. Dosbaeva, D.L. Wainstein, A. Biksa and A.Y. Rashkovskiy, Emergent behavior of nano-multilayered coatings during dry high speed machining of hardened tool steels, Surf. Coat. Technol. 204 (2010) 3425-3435. 
[23] C. Zehnder, J.-N. Peltzer, J.S.K.-L. Gibson, S. Korte-Kerzel, High strain rate testing at the nano-scale: a proposed methodology for impact nanoindentation, Mater. Design $151(2018)$ 17-28.

[24] Y.-W. Rhee, H.-W. Kim, Y. Deng, B.R. Lawn, Brittle fracture versus quasi-plasticity in ceramics: a simple predictive index. J. Am. Ceram. Soc. 2001, 84, 561-565. DOI: 10.1111/j.1151-2916.2001.tb00698.x. 
2020-10-06

Nano- and micro-scale impact testing of zirconia, alumina and zirconia-alumina duplex optical coatings on glass

\section{Beake, Ben D.}

Elsevier

Beake BD, Isern L, Bhattacharyya D, et al., (2020) Nano- and micro-scale impact testing of zirconia, alumina and zirconia-alumina duplex optical coatings on glass. Wear, Volumes 462-463, December 2020, Article number 203499

https://doi.org/10.1016/j.wear.2020.203499

Downloaded from Cranfield Library Services E-Repository 